\title{
Erratum zu: Innovation und Legitimation in der Migrationspolitik
}

Roswitha Pioch und Katrin Toens

\section{Erratum zu: \\ R. Pioch und K. Toens (Hrsg.), Innovation und Legitimation in der Migrationspolitik, Politikwissenschaft, politische Praxis und Soziale Arbeit im Dialog, https://doi.org/10.1007/978-3-658-30097-5}

Auf S. X wurden bei Prof. Dr. Roland Roth die akademischen Titel ergänzt.

Auf S. 349 wurde eine Referenz ausgetauscht und durch eine revidierte Fassung ersetzt.

Die korrigierte Version des Kapitels ist verfügbar unter

https://doi.org/10.1007/978-3-658-30097-5_13,

https://doi.org/10.1007/978-3-658-30097-5_21,

https://doi.org/10.1007/978-3-658-30097-5

(C) Springer Fachmedien Wiesbaden GmbH, ein Teil von Springer Nature 2020

R. Pioch und K. Toens (Hrsg.), Innovation und Legitimation in der

Migrationspolitik, Studien zur Migrations- und Integrationspolitik,

https://doi.org/10.1007/978-3-658-30097-5_22 